\title{
Distribución parcial de Paragonimus (Digenea: Troglotrematidae) en Antioquia, por presencia de metacercarias en cangrejos dulciacuícolas
}

\author{
Mónica Uruburu ${ }^{1,2}$, Mabel Granada², Luz Elena Velásquez ${ }^{1,2}$ \\ ${ }^{1}$ Grupo Microbiología Ambiental, Escuela de Microbiología, Universidad de Antioquia, Medellín, Colombia \\ 2 Programa de Estudio y Control de Enfermedades Tropicales/PECET, Universidad de Antioquia, Medellín, \\ Colombia
}

Introducción. La paragonimosis, o distomatosis pulmonar, es una enfermedad con sintomatología similar a la observada en la tuberculosis. Es causada por parásitos del género Paragonimus (Digenea: Troglotrematidae). Las personas se infectan al consumir cangrejos crudos o mal cocidos, con metacercarias del parásito. El primer foco de paragonimosis humana en Colombia se registró durante 1995 en Urrao, Antioquia, donde se hallaron dos especies de cangrejos que hospedaban el parásito. En el 2005 se capturaron cangrejos con metacercarias de Paragonimus en Medellín, lo que motivó la búsqueda del parásito en otras localidades, mediante su presencia en estos crustáceos.

Objetivo. Establecer la distribución de Paragonimus en Antioquia, evaluando la presencia de metacercarias en macrocrustáceos braquiuros, dulciacuícolas.

Materiales y métodos. Desde 2005 hasta 2007 se capturaron cangrejos en 13 municipios antioqueños. Se relajaron y sacrificaron para la búsqueda del digeneo y la identificación taxonómica.

Resultados. En nueve municipios se capturaron 52 cangrejos, 42 (80,76\%) con metacercarias de Paragonimus. Todos los crustáceos se determinaron como Pseudothelphusidae, de los géneros Hypolobocera y Strengeriana, y se asignaron a cuatro especies. Tres se registran por primera vez como huéspedes del parásito.

Conclusión. Se inicia la construcción de un mapa con la distribución de Paragonimus en Antioquia que incluye por primera vez zonas urbanizadas. Se ratifican el consumo y la manipulación de los cangrejos crudos y mal cocidos como factores de riesgo para la infección humana. Se propone a los cangrejos como agentes focalizadores de paragonimosis por ser asequibles y de fácil diagnóstico.

Palabras clave: braquiuros, Colombia, interacciones huésped-parásitos, localización geográfica de riesgo, Paragonimus, trematodos.

Distribution of Paragonimus (Digenea: Troglotrematidae) in Antioquia Province, Colombia, based on metacercariae counts in freshwater crabs

Introduction. Paragonimosis or lung fluke disease courses with signs similar to those seen in tuberculosis. The causative agent is a parasite of the genus Paragonimus (Digenea: Troglotrematidae). People become infected by ingesting raw or partially cooked crabs containing metacercariae. The first focus of human paragonimosis in Colombia was recorded in the county of Urrao, where two species of crabs infected with Paragonimus were found. In 2005, crabs with Paragonimus' metacercariae were captured near Medellín, western Colombia. This prompted a search for the parasite in other locations through its presence in the crabs.

Objective. To establish the distribution of Paragonimus in Antioquia, we evaluated the presence of metacercaria in freshwater brachyuran crabs.

Materials and methods. From 2005 to 2007, crabs were captured in 13 counties of Antioquia. The crabs were relaxed and dissected to determine presence of trematodes and then to make the taxonomic identifications. 
Results. From 52 crabs captured in 9 counties, 42 (80.8\%) were found with Paragonimus metacercariae. The crabs were identified as Pseudothelphusidae in 2 genera-Hypolobocera and Strengeriana - and were assigned to four species. Three of the species were recorded for the first time as hosts of Paragonimus.

Conclusions. A Paragonimus' distribution map was constructed for Antioquia; for the first time urban zones were included. Because of the high rate of infection, the handling and consumption of raw and poorly cooked crabs pose risk factors for human infection. Because crabs are affordable and provide means of easy diagnosis, crabs are targeted as primary agents of and diagnostic tools for paragonmosis.

Key words: Brachyura, Colombia, geographical localization of risk, host-parasite interactions, Trematoda, Paragonimus.

La paragonimosis, o distomatosis pulmonar, es una antropozoonosis endémica de algunos países tropicales y subtropicales de Asia, África y América, en donde afecta cerca de 22 millones de personas (1); se calcula que 293 millones están en riesgo de infectarse. Los agentes etiológicos de la enfermedad son diversas especies de Paragonimus (Digenea: Troglotrematidae), endoparásitos que desarrollan su ciclo de vida en tres huéspedes. El primero de ellos, un caracol dulciacuícola, en el cual se generan redias por reproducción asexual, las que a su vez producen cercarias.

Éstas salen del molusco y entran en el segundo huésped intermediario, un crustáceo, en el cual se transforman en metacercarias, formas infectantes para los huéspedes definitivos, mamíferos que las adquieren al consumir crustáceos crudos o mal cocidos (2-4).

Del sistema digestivo del mamífero, las metacercarias migran a través del peritoneo y el diafragma hasta llegar al pulmón, y ocasionalmente a otros órganos, donde se alojan y se transforman en adultos. Éstos, mediante reproducción sexual producen huevos, que salen con el esputo y son expulsados por la boca o las heces. En el exterior y en un ambiente acuático, los huevos inician su desarrollo embrionario; luego de varios días, eclosiona un miracidio, que busca

\footnotetext{
Correspondencia:

Luz Elena Velásquez, Calle 62 № 52-59, Sede de Investigación Universitaria (SIU), laboratorio 730.

Teléfono: (574) 219 6514; Fax: 2196511.

luzelena333@yahoo.com

Recibido: 12/06/08; aceptado:04/09/08
}

al molusco huésped y lo penetra, dando inicio a la reproducción asexual (4).

El parásito en el pulmón de los pacientes explica los signos y síntomas de la enfermedad: tos persistente con expectoración hemoptoica, acompañada de cavitaciones pulmonares, cuadro muy similar al presentado en la tuberculosis, lo que genera confusión en el diagnóstico y, por lo tanto, en el tratamiento y pronóstico $(2,5)$.

La paragonimosis es de evolución crónica y no es contagiosa (6). Pertenece al grupo de parasitosis cuyos factores de riesgo están relacionados con aspectos del hábitat de los pacientes, como la presencia de fuentes de agua naturales con cangrejos, considerados alimento para la comunidad. Otros factores de riesgo son la pobreza y aspectos culturales (2).

En Colombia se publicó la presencia de Paragonimus por primera vez en 1968, con el hallazgo de un foco silvestre en el Valle del Cauca (7). Los casos de paragonimosis humana sólo se comienzan a registrar a partir de 1981 (8). A su vez, el primer foco de paragonimosis humana se publica en 1995, en un resguardo indígena, en Urrao, Antioquia (9). En esta investigación la prevalencia del parásito en las personas fue de $10 \%$ y en los cangrejos de $50 \%$ a $90 \%$. De estos últimos, se determinaron dos especies como huéspedes del digeneo: Hypolobocera bouvieri monticola (Zimmer, 1912) e H. emberarum (Campos \& Rodríguez, 1995). El estudio también evidenció la importancia de dichos crustáceos como recurso alimentario para la comunidad embera $(4,10)$. Dos años después en esta localidad se estableció en 1,6\% la tasa de infección en el caracol huésped Aroapyrgus sp. (11). 
Posteriormente, durante 2003, se hallaron metacercarias de Paragonimus en cangrejos capturados en áreas rurales de Fredonia y, más adelante, durante el 2005, se encontraron estas mismas larvas en cangrejos de una zona periurbana de Medellín. Los hechos se consideraron evidencias para inferir que la distribución y el riesgo de infección con Paragonimus podrían estar siendo subvalorados en Antioquia; máxime cuando a lo anterior se sumó la riqueza hídrica del departamento y la abundancia de cangrejos en esos ecosistemas. Por lo tanto, se propuso realizar esta investigación con el fin de iniciar un mapa de distribución de Paragonimus, por medio del hallazgo de metacercarias en los cangrejos; estableciendo a su vez, la riqueza de las especies huéspedes.

\section{Materiales y métodos}

Desde 2005 hasta mediados de 2007, se visitaron varios municipios de Antioquia para recolectar cangrejos dulciacuícolas. Las coordenadas de los sitios de captura se establecieron por medio de un Global Positioning System (GPS) (sistema de información geográfica, SIG). Los especímenes capturados se trasladaron vivos al Laboratorio de Malacología Médica y Tremátodos, PECET, Universidad de Antioquia, donde se mantuvieron hasta por dos días, en acuarios adecuados con agua declorinada, aireación permanente y fotoperíodo 12:12.

Para establecer el estatus taxonómico y el desempeño como huéspedes de digéneos, los cangrejos se sacrificaron con choque térmico, en agua a $2^{\circ} \mathrm{C}$ durante 10 minutos, técnica que se estandarizó en el Laboratorio de Malacología Médica y Tremátodos. Luego, el cefalotórax de cada espécimen se separó en dos partes y cada una se examinó al estereomicroscopio en busca de metacercarias.

Las metacercarias de cada cangrejo se pasaron a cajas de Petri con agua declorinada para clasificarlas según su morfología y contabilizarlas.

Las metacercarias de Paragonimus se observaron al microscopio para estimar con un micrómetro ocular el largo y el ancho del cuerpo, los diámetros de la ventosa oral y el acetábulo, y la distancia entre éstas. Las dimensiones se dan en milímetros. Se hicieron, además, registros fotográficos. Posteriormente, tanto los cangrejos como los parásitos, se conservaron en frascos plásticos con alcohol al $70 \%$.

La determinación taxonómica de los cangrejos parasitados con Paragonimus se estableció por medio de la morfología de los gonópodos y del tercer maxilípedo, utilizando las claves y descripciones publicadas (12-15). De cada localidad se depositaron y codificaron especímenes en la Colección de Referencia de Crustáceos del Museo Universitario de la Universidad de Antioquia.

En el diseño del mapa de distribución de Paragonimus se utilizó el programa DIVA-GIS 5.2.

\section{Resultados}

En nueve municipios de Antioquia se capturaron 52 cangrejos; de $42(80,76 \%)$ se aislaron 222 metacercarias de Paragonimus $(10,16)$. Todas las larvas se encontraron reptando en el sistema digestivo de los cangrejos, excepto una que presentó una pared quística delgada; ésta se rasgó al montarla entre el portaobjetos y el cubreobjetos. Se caracterizaron por el color rosa intenso del cuerpo, en contraste con el tono claro de los ciegos intestinales y el pigmento negro del sistema excretor. Otro rasgo constante fue el promedio del diámetro de la ventosa oral que corresponde a dos tercios del diámetro del acetábulo; este último se encuentra localizado en la región ecuatorial. La ventosa oral se continúa en una faringe corta y musculosa que luego se bifurca en los ciegos intestinales, los cuales se proyectan hasta la región posterior, donde se encuentra, además, el poro excretor en posición terminal (figura 1). Las dimensiones de las principales estructuras estimadas en 63 especímenes se presentan en el cuadro 1.

En cuanto al número de metacercarias de Paragonimus por huésped y por localidad, se obtuvo un rango de variación amplio (cuadro 2). De los crustáceos recolectados en los municipios Cañasgordas y Medellín, se extrajeron 39 y 57 parásitos, respectivamente. En contraste, de algunos cangrejos de Hispania, Fredonia, San Luis 
y Caramanta, se extrajo sólo una metacercaria de Paragonimus.

En varios cangrejos huéspedes de Paragonimus se presentó el hallazgo incidental de quistes pertenecientes a otros digeneos, localizados en

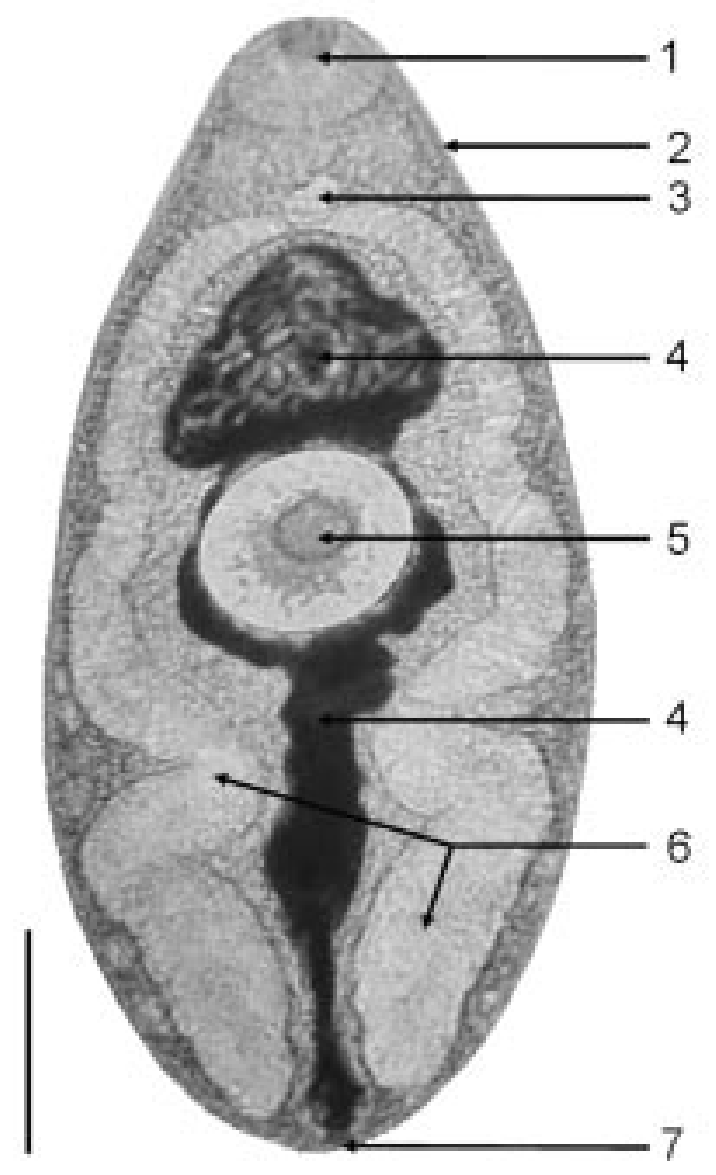

Figura 1. Metacercaria de Paragonimus: 1. Ventosa oral, 2. Parénquima, 3. Faringe, 4. Sistema excretor, 5. Acetábulo, 6. Ciegos intestinales, 7. Poro excretor. Barra: 0,2 mm. Fotografía tomada en el Laboratorio de Malacología Médica y Tremátodos. las branquias y en el sistema digestivo. Los especímenes se contabilizaron y fijaron en alcohol, para investigaciones futuras (cuadro 2).

Respecto al estatus taxonómico de los cangrejos infectados con Paragonimus, se estableció que todos se encuentran asignados a la familia Pseudothelphusidae Rathbun, 1893, endémica de la región neotropical y que corresponden a cuatro especies, tres de ellas del género Strengeriana Pretzmann, 1971, y una del género Hypolobocera Ortmann, 1897.

Se determinó a Strengeriana fuhrmanni (Zimmer, 1912), recolectada en los municipios de Ciudad Bolívar (MU-CR 0078), Caramanta (MU-CR 0080) y Fredonia (MU-CR 0064). Ésta fue la especie más ubicua del género. Strengeriana bolivarensis (Rodríguez \& Campos, 1989), hallada en Hispania (MUCR 0079) y Strengeriana sp. recolectada en San Luis, están por describirse.

Todos los Hypolobocera se determinaron como H. bouvieri (Rathbun, 1898), y fueron recolectados en Cañasgordas (MU-CR 0061), Envigado (MUCR 0091), Girardota (MU-CR 0056) y Medellín (MU-CR 0057).

\section{Discusión}

Al utilizar las metacercarias de Paragonimus para la construcción del mapa sobre su distribución en Antioquia, la presencia del digeneo ha pasado de $0,8 \%$ a $8 \%$ de los municipios del departamento. Este incremento pone de manifiesto un rango de distribución del parásito más amplio de lo esperado (figura 2), que cubre incluso sectores urbanos como Medellín, donde se registró el mayor número de metacercarias de Paragonimus/ cangrejo. Este hecho evidencia la tolerancia del parásito a la presión del urbanismo sobre las

Cuadro 1. Dimensiones de algunas estructuras de las metacercarias de Paragonimus obtenidas en cangrejos de nueve municipios de Antioquia. Para cada parámetro se dan el rango y el promedio en $\mathrm{mm}$, con base en 63 especímenes medidos.

\begin{tabular}{lcccc}
\hline $\begin{array}{l}\text { Estructuras de } \\
\text { metacercarias }\end{array}$ & Largo & Ancho & $\begin{array}{c}\text { Diámetro ventosa } \\
\text { oral }\end{array}$ & $\begin{array}{c}\text { Diámetro } \\
\text { acetábulo }\end{array}$ \\
\hline Rango y promedio & $0,81-1,18$ & $0,40-0,54$ & $0,11-0,14$ & $0,16-0,24$ \\
& $(0,97)$ & $(0,49)$ & $(0,13)$ & $(0,2)$ \\
\hline
\end{tabular}


Cuadro 2. Sitios de captura de los cangrejos infectados con metacercarias de Paragonimus, cantidad de éstas y de quistes de otros digéneos.

\begin{tabular}{|c|c|c|c|c|}
\hline Municipio & Coordenadas & $\begin{array}{c}\text { Cangrejos positivos/ } \\
\text { disecados }\end{array}$ & $\begin{array}{c}\text { № de metacercarias } \\
\text { Paragonimus }\end{array}$ & $\begin{array}{l}\text { № de otras } \\
\text { metacercarias }\end{array}$ \\
\hline Cañasgordas & $\begin{array}{c}N 6^{\circ} 44^{\prime} 8^{\prime \prime} \\
\text { WO } 76^{\circ} 01^{\prime} 0.8^{\prime \prime}\end{array}$ & $1 / 1$ & 39 & 0 \\
\hline Caramanta & $\begin{array}{c}\text { N 5o } 34^{\prime} 17^{\prime \prime} \\
\text { WO 75" } 36^{\prime} 15^{\prime \prime}\end{array}$ & $11 / 12$ & 36 & 19 \\
\hline Ciudad Bolívar & $\begin{array}{l}\text { N 5 } 52^{\prime} 11^{\prime \prime} \\
\text { WO } 76^{\circ} 02^{\prime} 4^{\prime \prime}\end{array}$ & $1 / 1$ & 10 & 2 \\
\hline Envigado & $\begin{array}{l}\text { N 6o } 103^{\prime} 18^{\prime \prime} \\
\text { WO 75을 } 33^{\prime} 4^{\prime \prime}\end{array}$ & $1 / 1$ & 4 & 0 \\
\hline Fredonia & $\begin{array}{c}\text { N 5 } 54^{\prime} 6^{\prime \prime} \\
\text { WO 75 } 44^{\prime} 7^{\prime \prime} \\
\text { N 5 } 59^{\circ} 3^{\prime \prime} \\
\text { WO } 75^{\circ} 40^{\prime} 14^{\prime \prime}\end{array}$ & $\begin{array}{c}17 / 23 \\
2 / 4\end{array}$ & $\begin{array}{l}27 \\
2\end{array}$ & $\begin{array}{r}0 \\
157\end{array}$ \\
\hline Girardota & $\begin{array}{c}\text { N 6²2'1"' } \\
\text { WO 75²7'9"' }\end{array}$ & $1 / 1$ & 15 & 3 \\
\hline Hispania & $\begin{array}{c}N 5^{\circ} 48^{\prime} 6^{\prime \prime} \\
\text { WO } 75^{\circ} 53^{\prime} 7^{\prime \prime}\end{array}$ & $1 / 2$ & 1 & 11 \\
\hline Medellín & $\begin{array}{l}\text { N 6 } 16^{\prime} 12^{\prime \prime} \\
\text { WO } 75^{\circ} 36^{\prime} 9^{\prime \prime} \\
\text { N 6 } 13^{\circ} 15^{\prime \prime} \\
\text { WO } 75^{\circ} 33^{\prime} 4^{\prime \prime}\end{array}$ & $\begin{array}{l}3 / 3 \\
1 / 1\end{array}$ & $\begin{array}{r}79 \\
4\end{array}$ & $\begin{array}{r}294 \\
0\end{array}$ \\
\hline $\begin{array}{l}\text { San Luís } \\
\text { Total }\end{array}$ & $\begin{array}{c}\text { N 5 } 55^{\prime} 9^{\prime \prime} \\
\text { WO } 74^{\circ} 45^{\prime} 10^{\prime \prime}\end{array}$ & $\begin{array}{c}3 / 3 \\
42 / 52\end{array}$ & $\begin{array}{r}5 \\
222\end{array}$ & $\begin{array}{l}503 \\
989\end{array}$ \\
\hline
\end{tabular}

cuencas hidrográficas de la ciudad (17), al tiempo que revalúa el supuesto de que el digeneo está restringido a zonas rurales y selváticas, lo que de manera implícita dejaba los centros urbanizados fuera de riesgo. Por lo tanto, es preciso que las campañas de divulgación sobre la parasitosis y sus factores de riesgo, sean diseñadas para las zonas rurales y las cabeceras municipales.

Acerca de los crustáceos, se confirma que en la relación con Paragonimus no hay una alta especificidad, pues se encontraron cuatro especies de Pseudothelphusidae infectadas con el parásito, de las ocho registradas para Antioquia (14). Se registran por primera vez como huéspedas del parásito tres especies: Strengeriana fuhrmanni, S. bolivarenses y Strengeriana sp., que entran a engrosar la larga lista de huéspedes secundarios en Suramérica $(2,18,19)$.

Para Hypolobocera bouvieri, señalado como huésped de Paragonimus en Urrao en 1995, se extiende el rango de distribución como huésped de dicho parásito a cuatro municipios: Cañasgordas, Envigado, Girardota y Medellín $(9,16)$. Este género también había ha sido señalado en Perú como huésped del parásito (19).

De otro lado, la alta frecuencia de cangrejos infectados con Paragonimus demuestra que tanto los moluscos huéspedes (Aroapyrgus spp.) como los huéspedes definitivos presentan una amplia distribución geográfica. Acerca de los mamíferos, recientemente se demostró el papel de Didelphys marsupialis como reservorio del digeneo en Antioquia, hecho ya registrado en otros países de Centroamérica y Suramérica (17). Respecto a los didélfidos, es importante considerar que frecuentan el peridomicilio de los sectores rurales y semirurales, y además, constituyen una fuente de alimento para algunas comunidades.

Estos resultados son una muestra de la situación dentro del sistema andino, en el cual se comparten 


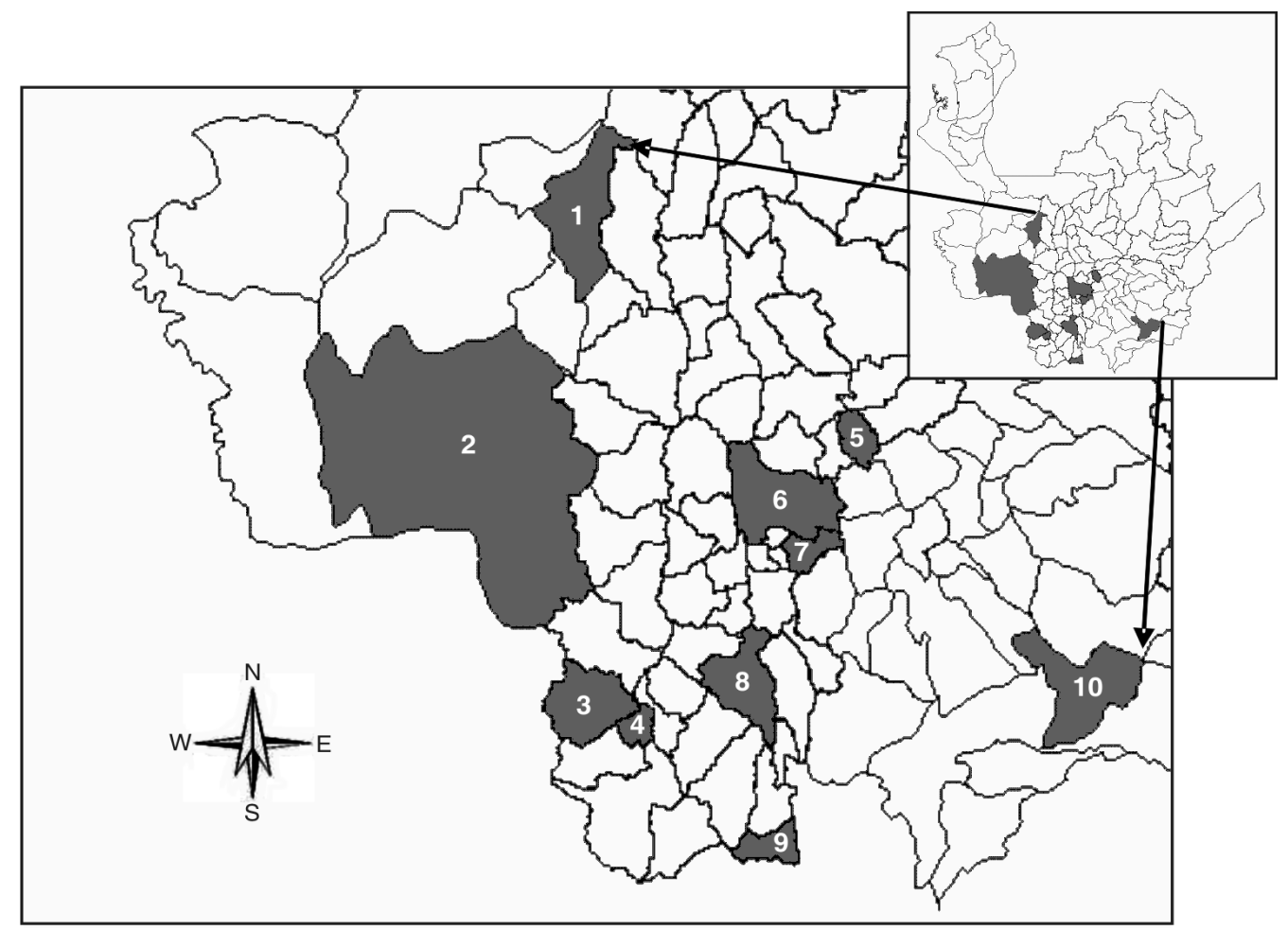

Figura 2. Mapa de distribución parcial de Paragonimus en Antioquia:1. Cañasgordas, 2. Urrao, 3. Ciudad Bolívar, 4. Hispania, 5. Girardota, 6. Medellín, 7. Envigado, 8. Fredonia, 9. Caramanta, 10. San Luis.

condiciones ecológicas y las interacciones huésped-parásito son similares.

Esta investigación lleva a considerar la amplia distribución de Paragonimus en Antioquia como un riesgo de infección mayor del esperado, para personas, animales domésticos y silvestres, e invita a continuar develando la distribución geográfica del digeneo en los demás municipios de Antioquia y los otros departamentos del país.

También los resultados de este trabajo permiten proponer a los cangrejos como indicadores de foco de paragonimosis, debido a que son más fáciles de obtener en el campo y de evaluar en el laboratorio, que los caracoles huéspedes. De igual forma, la disección, extracción e identificación de las metacercarias sólo requieren un entrenamiento corto.

Las metacercarias de Paragonimus, a su vez, constituyen una oportunidad para adelantar estudios moleculares en taxonomía e inmunodiagnóstico, alternativas que se trabajan en los países donde existe una gran prevalencia de paragonimosis (20-23).

\section{Agradecimientos}

A Martha R. Campos por su valiosa colaboración en la confirmación de las especies de cangrejos encontrados con metacercarias de Paragonimus; a Imelda Vélez por su acompañamiento y contribución como trematóloga, a Iván Darío Vélez, Director del PECET por su constante apoyo, y a los compañeros del Laboratorio de Malacología Médica y Tremátodos.

\section{Conflicto de intereses}

Las autoras declaramos que no existen conflictos de intereses en el desarrollo y publicación de este trabajo.

\section{Financiación}

Esta investigación fue financiada por el programa de incentivos a la investigación estudiantil, del 
Museo Universitario de la Universidad de Antioquia, a mediante el proyecto "Montaje de la colección de cangrejos de aguas continentales de Antioquia en el Museo Universitario".

\section{Referencias}

1. Nabakumar ST, Rebachandra SH, Sulochana Dk, Brajachand SN, Ibotomba SY. Pulmonary Paragonimiasis. Indian J Chest Dis Allied Sci. 2004;46:225-27.

2. OMS. Serie de informes técnicos. Lucha contra las trematodiasis de transmisión alimentaria. Ginebra: Organización Mundial de la Salud; 1995.

3. Keiser J, Utzinger J. Emerging foodborne trematodiasis. Emerg Infect Dis. 2005;11:1507-14.

4. Vélez ID, Velásquez LE. Paragonimosis una investigación multidisciplinaria en salud, biología y cultura en Colombia. Medellín: Editorial Universidad de Antioquia; 2002.

5. Alvarado L, Pariona R, Beltrán M. Casos de paragonimiasis (Paragonimiosis) en el Hospital Nacional Sergio E. Bernales (Lima, Perú). Rev Peru Med Exp Salud Pública. 2004;21:107-10.

6. Rumbea GJ. Paragonimiasis. Enfermedades infecciosas y parasitarias. Sao Paulo; 1982.

7. Little MD. Paragonimus caliensis sp. and paragonimiasis en Colombia. J Parasitol. 1968;54:738-46.

8. Buitrago B, Rodríguez G, Gómez G, Abril A. Paragonimiasis humana. Primera descripción de un caso colombiano. Biomédica. 1981;1:142-51.

9. Vélez ID, Ortega J, Hurtado M, Salazar AL. La paragonimosis en la comunidad indígena Embera de Colombia. Biomédica. 1995;27:51-4.

10. Vélez ID, Ortega J, Hurtado MI, Salazar AL, Robledo SM, Jiménez JN, et al. Epidemiology of paragonimiasis in Colombia. Trans R Soc Trop Med Hyg. 2000;94:1-3.

11. Velásquez LE, Restrepo S, Gómez MI, Velez I. Aspectos epidemiológicos del caracol Aroapyrgus sp. Rev Asoc Col Cienc Biol. 1999;11:7-15.

12. Campos RM, Rodríguez G. Three new species of Strengeriana from Colombia (Crustacea: Decápoda: Pseudothelphusidae). Proc Biol Soc Wash. 1993;106:508-13.
13. Campos RM, Rodríguez G. Two new species of freshwater crabs of genus Hypolobocera from Colombia (Crustacea: Decápoda: Pseudothelphusidae). Proc Biol Soc Wash. 1995;108:649-55.

14. Campos RM. A review of the freshwater crabs of the genus Hypolobocera Ortmann, 1897 (Crustacea: Decapoda: Brachyura: Pseudothelphusidae), from Colombia. Proc Biol Soc Wash. 2003;116:754-802.

15. Campos RM. Freshwater crabs from Colombia. A taxonomic and distributional study. Bogotá, D.C.: Editorial Guadalupe Ltda.; 2005.

16. Vélez I, Velásquez LE, Vélez ID. Morphological description and life cycle of Paragonimus sp. (Trematoda: Troglotrematidae): causal agent of human paragonimiasis in Colombia. J Parasitol. 2003;89:749-55.

17. Gómez C, Valencia E, Velásquez LE. Estudio de foco de Paragonimus en Fuente Clara, Robledo área periurbana de Medellín, Antioquia (tesis). Medellín: Universidad de Antioquia; 2007.

18. Lamothe-Argumedo R. La paragonimosis en el continente americano. Salud Pública Mex. 1985;27:51423.

19. Rodríguez G, Magalhaes C. Recent advances in the biology of the Neotropical freshwater crab family Pseudothelphusidae (Crustacea, Decapoda, Brachiura). Rev Bras Zool. 2005;22:354-65.

20. Ikeda T. Cystatin capture enzyme-linked immunosorbent assay for immunodiagnosis of human paragonimiasis and fascioliasis. Am J Trop Med Hyg. 1998;59:286-90.

21. Sugiyama H, Morishima $\mathbf{Y}$, Kameoka $\mathbf{Y}$, Kawanaka M. Polymerase chain reaction (PCR)-based molecular discrimination between Paragonimus westermani and P. miyazakii at the metacercarial stage. Mol Cell Probes. 2002;16:231-6.

22. Narain K, Rekha DK, Mahanta J. Development of enzyme-linked immunosorbent assay for serodiagnosis of human paragonimiasis. Indian $\mathrm{J}$ Med Res. 2005;121:739-46.

23. Rekha Dk, Narain K, Bhattacharya S, Negmu K, Agatsuma T, Blair D, et al. Pleuropulmonary paragonimiasis due to Paragonimus heterotremus: molecular diagnosis, prevalence of infection and clinicoradiological features in an endemic area of northeastern India. Trans R Soc Trop Med Hyg. 2007;101:786-92. 